Revista Complutense de Historia de América

ISSN: 1132-8312

http://dx.doi.org/10.5209/RCHA.61087

\title{
Radiografía de una transición. México y la democratización de España en 1977
}

\author{
Carlos Sola Ayape ${ }^{1}$
}

Recibido: 10 de marzo de 2017 / Aceptado: 15 de febrero de 2018

Resumen. Tras el 40 aniversario del establecimiento de las relaciones bilaterales entre México y España, acaecido en París el 28 de marzo de 1977, el objetivo del presente artículo es presentar y analizar las valoraciones del México del presidente José López-Portillo sobre la transición democrática española en 1977, un año especialmente clave no sólo para la democratización de España, sino para la normalización definitiva del vínculo diplomático hispano-mexicano, después de permanecer 40 años condicionado por las consecuencias de la Guerra Civil española.

Palabras clave: Exilio español; nacionalismo revolucionario; establecimiento de relaciones hispanomexicanas; transición democrática española; Pactos de la Moncloa; embajador José Gómez Gordoa; presidente José López-Portillo; presidente Adolfo Suárez; rey Juan Carlos I.

\section{[en] X-Ray of a transition. Mexico and the democratization of Spain in 1977}

Abstract. After the 40th anniversary of the establishment of bilateral relations between Mexico and Spain -Paris, March 28, 1977- the objective of this article is to present and analyze Mexico's assessments, during the presidency of José López-Portillo, of Spain's transition to democracy in 1977, a year especially important not only for the democratization of Spain, but also for the definitive normalization of the Spanish-Mexican diplomatic bond, after 40 years of being conditioned by the consequences of the Spanish Civil War.

Keywords: Spanish Exile; Revolutionary Nationalism; Establishment of Spanish-Mexican Relations; Spanish Democratic Transition; Pacts of Moncloa; Ambassador José Gómez Gordoa; President José López-Portillo; President Adolfo Suárez; King Juan Carlos I.

Sumario. 1. México y España, 40 aniversario: a modo de introducción. 2. El informe del embajador Gómez Gordoa. 3. México ante la política exterior española hacia América Latina 4. Valoraciones finales. 5. Referencias bibliográficas.

Cómo citar: Sola Ayape, C. (2018) Radiografía de una transición. México y la democratización de España en 1977, en Revista Complutense de Historia de América 44, 235-260.

1 Tecnológico de Monterrey, Escuela de Humanidades y Educación, Vicerrectoría de Investigación, Posgrados y Educación Continua (México)

E-mail: csola@itesm.mx 
El tránsito de la dictadura a la democracia, manejada con una habilidad evidente por S. M. el Rey y Adolfo Suárez, ha pasado momentos dramáticos que quizás pusieron al país al borde de un golpe militar, especialmente al legalizarse el Partido Comunista y al aprobarse la Ley de Amnistía.

(José Gómez Gordoa, embajador de México en España, noviembre de 1977)

\section{México y España, 40 aniversario: a modo de introducción}

El 28 de marzo de 1977 tuvo lugar el "establecimiento" de las relaciones diplomáticas entre México y España, dos países cuyo destino común estuvo marcado, durante cuatro largas décadas del siglo XX, por las consecuencias de la Guerra Civil española (1936-1939). El posicionamiento del presidente Lázaro Cárdenas en favor del bando republicano del presidente Manuel Azaña y la posterior implantación del régimen militar del general Francisco Franco condicionaron sobremanera la forma en que México se acercó, y además de manera muy distinta, a aquellas dos Españas: relaciones oficiales con la republicana del exilio y relaciones oficiosas con la franquista.

La larga duración de la dictadura provocó, entre otros efectos, que siete presidentes mexicanos se negaran -sexenio tras sexenio- a reconocer al régimen franquista, en lo que acabó siendo no sólo una razón de Estado, sino una de las principales premisas que caracterizó a aquel régimen revolucionario en materia de política exterior. El mensaje fue concebido para los de afuera, pero también para los de adentro. El presidencialismo mexicano, institucionalizado al abrigo de la alargada sombra de la revolución, supo sacar su particular rédito político al negar la mano a dictaduras como la franquista, al presumir de valores democráticos y al avalar su postura internacional sobre el sustento jurídico de unos principios torales como la defensa a ultranza de la soberanía nacional y el respeto escrupuloso al principio de no intervención.

No hay que olvidar que, durante 40 años, México defendió congruentemente que la Guerra Civil había sido el producto de un atentado contra la soberanía del pueblo español, encarnada en unas instituciones republicanas legal y legítimamente constituidas, y que la insurgencia militar rebelde, lejos de haber sido un cuartelazo doméstico, había respondido a una estrategia de mayor alcance, al contar, durante el desarrollo de la guerra, con el apoyo de las potencias nazi-fascistas como la Alemania de Hitler y la Italia de Mussolini. Por ello, México sostuvo, década tras década, la tesis de la internacionalización de aquel conflicto armado y la conculcación de los principios que animaban la carta de la ginebrina Sociedad de las Naciones. De hecho, sus representantes diplomáticos en la Liga -Narciso Bassols, Isidro Fabela o Primo Villa Michel- no cejaron en su empeño de mostrar y demostrar que la tragedia que venía desangrando España no era sino el presagio de la gran conflagración que se avecinaba: la Segunda Guerra Mundial².

Pero al margen de estos detalles, lo cierto es que el tiempo terminó demostrando que la muerte de Franco -el 20 de noviembre de 1975- no supuso el fin de los obstá-

2 Al respecto, véase Sánchez - Herrera, 2011; Jorge, 2016; Sola Ayape, 2016a. 
culos que venían condicionando el enquistamiento de las relaciones bilaterales entre México y la España del rey Juan Carlos. Dicho de otro modo, el acercamiento entre nuestros dos países también necesitó de su propia transición, como lo demuestra el hecho de que la normalización del vínculo diplomático tuvo lugar año y medio después de la desaparición física del general Franco ${ }^{3}$.

A unas semanas de su toma de protesta - primero de diciembre de 1976-el presidente electo José López-Portillo ordenó a Santiago Roel -su hombre fuerte durante la campaña electoral en materia de política exterior y al que, poco después, le entregaría la titularidad de la Secretaría de Relaciones Exteriores-a que viajase a Madrid con el fin de hacer la "auscultaciones pertinentes" con las autoridades españolas. El propósito no era otro que el de visualizar un horizonte cercano donde tuviera lugar la normalización de las relaciones diplomáticas entre México y aquella España sin Franco, pero con rey. Recordemos que, para ese entonces, México todavía tenía relaciones diplomáticas con el gobierno de la República Española en el Exilio, una vieja relación que, como se dice, venía desde los años 30 cuando el presidente Cárdenas apoyó al gobierno republicano en la Guerra Civil española. Durante cuatro décadas, México había defendido, también en foros internacionales como la Liga de las Naciones durante los años 30 o la Organización de las Naciones Unidas ya a partir de 1945, lo que en Tlatelolco se conoció como la "postura vertical", ese corolario de principios legales y jurídicos de los que se dotó México para concebir la naturaleza de su relación con respeto a las dos Españas: la peregrina del exilio y la franquista ${ }^{4}$.

Después, y ya en su condición de secretario de Relaciones Exteriores, el canciller Roel fue el elegido para establecer relaciones con España. El acto protocolario tuvo lugar el 28 de marzo de 1977 en el hotel Jorge V de París; allí se reunió con su homólogo el ministro de Asuntos Exteriores español, Marcelino Oreja, y a través de un sencillo canje de notas se logró el establecimiento de las relaciones diplomáticas entre México y España. Ambos países dejaban resueltas sus diferencias para encarar una relación bilateral sustentada en la cooperación y el respeto recíproco que, con estos principios rectores, ha llegado como tal hasta nuestros días.

En este sentido, el acopio y estudio de las fuentes documentales, provenientes de la Secretaría de Relaciones Exteriores, incluida la propia embajada de México en España, nos demuestran el gran interés suscitado dentro de esta dependencia de la administración lópez-portillista por la evolución política española y, en general, por todos los pormenores -actos, actores, condiciones y condicionantes- de aquel complejo tránsito de una dictadura manu militari a un Estado de Derecho ${ }^{5}$. El rigor analítico que caracterizó a

Sola Ayape, 2010a y 2011.

$4 \quad$ Sola Ayape, 2016b. Un buen y reciente estudio sobre las relaciones bilaterales hispano-mexicanas -nutridas de encuentros y desencuentros- desde el siglo XIX hasta la fecha, véase en Sánchez - Pérez, 2015. También, Matesanz, 1980 y Cordero, 2005. Acerca de la mirada de la prensa mexicana sobre la transición española en Sánchez, 2007.

5 A modo de ejemplo, y de los muchos que podrían mostrarse al respecto, baste recordar la carta que el secretario de Relaciones Exteriores de México, Alfonso García Robles, escribía un 12 de marzo de 1976 a su embajador en Francia, el escritor Carlos Fuentes, donde se le reconocía, a modo de agradecimiento, los contactos que venía manteniendo en Francia, entre otros, con personajes tan importantes del exilio español como José Maldonado o Fernando Valera. El canciller mexicano consideraba para la ocasión de "gran utilidad" dichas conversaciones, puesto que permitían "tener acceso a opiniones autorizadas sobre la evolución de los acontecimientos en España que, como no escapará a su reconocido buen criterio, interesan particularmente a nuestro país". Carta de Alfonso García Robles a Carlos Fuentes. Ciudad de México, 12-III-1976. Archivo Histórico Genaro Estrada [México] (en adelante AHGE), Expediente III, núm. 3286-4. 
aquellos informes "confidenciales", nos advierte del puntual conocimiento que México tuvo en todo momento del devenir político de la democratización de España, tal y como se pondrá de manifiesto en las páginas siguientes. De este modo, y para la elaboración del presente manuscrito, se han seleccionado, de entre la documentación reunida, dos fuentes primarias de especial relevancia: la primera, un minucioso informe elaborado desde Madrid por el embajador mexicano José Gómez Gordoa y, la segunda, los documentos pertenecientes a la "carpeta operativa", preparada por la Dirección General del Servicio Diplomático de la Secretaría de Relaciones Exteriores, con motivo de la programación del viaje oficial a España del presidente López-Portillo, fijado para octubre de 1977. Como se verá más adelante, la relevancia de ambas fuentes documentales se debe en buena medida a que ambas datan de 1977, un año clave en el desenvolvimiento y éxito de aquella transición democrática española ${ }^{6}$.

\section{El informe del embajador Gómez Gordoa}

E1 23 de noviembre de 1977, y bajo el tenor "Situación política española", el embajador de México en España, José Gómez Gordoa, remitió desde Madrid un detallado informe a su secretario de Relaciones Exteriores, el licenciado Santiago Roel:

Me permito adjuntar a la presente -hizo explícito en sus primeras palabras-, una serie de datos relativos a la situación política española, resultado de mis conversaciones con los dirigentes de los 5 partidos más importantes de la política española, a saber: don Adolfo Suárez, don Felipe González, don Enrique Tierno Galván, don Manuel Fraga Iribarne y don Santiago Carrillo, así como de hombres de negocios, funcionarios y prensa en general ${ }^{7}$.

A su vez, y con respecto al pulso político de aquella España en transición hacia la democracia, Gómez Gordoa ponía en conocimiento del secretario el borrador constitucional de los "39 primeros artículos” que después fueron presentados "para su discusión y aprobación” por parte de las Cortes constituyentes españolas ${ }^{8}$.

6 Estas fuentes documentales presentan tres aspectos de gran interés: primero, son fuentes primarias; segundo, provienen de dependencias administrativas de alto rango dentro del organigrama de la secretaría encargada de las directrices de la política exterior de México y, tercero, su elaboración fue concebida para uso exclusivamente interno del personal diplomático, incluido el presidente de la República, José López-Portillo.

7 Informe de José Gómez Gordoa a Santiago Roel. Madrid, 23-XI-1977. AHGE, Expediente III, núm. $3302-2$. Desde el 3 de septiembre de 1977 -y tras el fugaz paso de 12 días de Gustavo Díaz Ordaz al frente de la recuperada embajada de México en España-, Gómez Gordoa ocupaba el cargo de Embajador Extraordinario y Plenipotenciario de México ante el gobierno español. De ascendencia santanderina y hasta entonces director del Banco Internacional, era un hombre ligado al mundo de las finanzas, experto en temas de economía española y con más de 40 viajes a España en su haber. La prensa mexicana recibió con agrado la noticia de su nombramiento, confiando en que haría una "una brillante carrera en España" y lograría "muy buenos logros comerciales para México". Basurto, 1977: 7 y 8. En efecto, su perfil neutro y neutral, sin ningún tipo de implicación política, lo desligaba de un pasado tan turbio, del que no pudo escapar Díaz Ordaz, como la matanza de Tlatelolco del 2 de octubre de 1968. Sobre el breve y polémico paso del ex presidente Díaz Ordaz como primer embajador de México en España tras el establecimiento de las relaciones diplomáticas, véase "Gustavo Díaz Ordaz: el embajador de los 12 días" en Sola Ayape, 2009: 118-153.

8 Ya tuvimos la ocasión de presentar un primer avance sobre la percepción mexicana de la democratización española en Sola Ayape, 2015b. 
De sus primeras palabras, se desprenden dos importantes conclusiones: la primera, que a fines de 1977 España se encontraba inmersa en un debate constitucional para la futura aprobación de una nueva carta magna y, la segunda, que el país ya contaba para ese entonces con un sólido entramado institucional de partidos políticos con representación parlamentaria -herencia de la última de las leyes fundamentales del "reino" franquista, esto es, la ley para la Reforma Política ratificada en referéndum el 15 de diciembre de 1976-, encabezados todos ellos por líderes de diferentes tendencias ideológicas, fiel reflejo de la compleja realidad política española del momento ${ }^{9}$. Implícitamente, y a la luz del perfil de sus dirigentes, se detecta la ausencia de formaciones republicanas en aquella nueva España monárquica, sin duda, uno de los requerimientos del gobierno, bajo el pretexto de "ser contrario a la forma de estado", tal y como argumentó el Ministerio de Gobernación encabezado por Rodolfo Martín Villa. Por consiguiente, todos los partidos políticos en disputa electoral habían aceptado, de una u otra forma, la controvertida presencia de la Corona al frente de la jefatura del Estado ${ }^{10}$.

Es importante destacar que, anexo al informe Gómez Gordoa, se encontraba un telegrama de Heriberto Barrera -en ese entonces secretario general de Esquerra Republicana de Catalunya- que, con fecha de 3 de mayo de 1977, había remitido al presidente José López-Portillo. Faltaba poco más de un mes para las primeras elecciones generales en España -15 de junio-, y en dicho comunicado se transmitía el siguiente mensaje:

Rogamos intercesión Vuestra Excelencia acerca gobierno español para hacer posible nuestra participación en próximas elecciones mediante la legalización inmediata de nuestro partido Esquerra Republicana de Catalunya que fue mayoritario en representación catalana Cortes españolas en parlamento y gobierno catalán autónomo hasta Guerra Civil $1936^{11}$.

Para añadir, a modo de cierre: "Inadmisible excluir de vida política los partidos republicanos. Respetuosamente" 12 .

A pesar de que la parquedad documental nos niega el eco que este mensaje tuvo en la presidencia de la República mexicana, todo hace indicar que su gobierno hizo oídos sordos a tal reclamo, especialmente, porque dos meses antes -el 18 de marzo- el gobierno de López-Portillo había forzado la situación para cancelar-que no

9 La regulación de los partidos políticos en aquella España en transición hacia la democracia se fue dando mediante la senda legal que surcó la ley 21/1976, de 14 de junio, sobre el derecho de asociación política; el decreto 2281/76, de 16 de septiembre, por el que se reguló el registro de asociaciones políticas y, finalmente, la ley 54/1978, de 4 de diciembre, sobre los partidos políticos.

10 La Corona fue una herencia del franquismo. Por la ley de Sucesión en la Jefatura del Estado de 1947, se estableció la constitución de España nuevamente en Reino y la sucesión de Francisco Franco como jefe del Estado español, al disponer que el sucesor sería propuesto por el propio Franco a título de Rey o de Regente del Reino, pero que tendría que ser aprobado por las Cortes españolas. Años después, el 22 de julio de 1969 el propio general Franco designó a Juan Carlos de Borbón como su sucesor a la Jefatura del Estado, con el título de "Príncipe de España”. Así fue proclamado por las Cortes como sucesor de Franco cuando Juan Carlos juró “fidelidad a los principios del Movimiento Nacional y demás Leyes Fundamentales del Reino". Tras el fallecimiento de Franco, Juan Carlos de Borbón fue proclamado jefe de Estado y coronado como rey de España el 22 de noviembre de 1975 en el Palacio de las Cortes.

11 Telegrama de Heriberto Barrera a José López-Portillo. Barcelona, 3-V-1977. AHGE, Expediente III, núm. $3302-2$.

12 Ibídem. 
romper- sus relaciones diplomáticas con el gobierno de la República Española en el Exilio ${ }^{13}$. Aquel acontecimiento - a la postre, una conditio sine qua non reclamada por el gobierno de Suárez para normalizar las relaciones diplomáticas con México-, dejaba tres importantes lecturas en clave política: la primera, que México quedaba libre para tener sus relaciones diplomáticas con la España juancarlista; la segunda, que México avalaba el proyecto de Estado diseñado por Franco y con el que arrancó la transición democrática a la muerte del dictador; $y$, la tercera, que México daba por finiquitada cualquier tentativa en España de regresar a la democracia por la vía republicana $^{14}$. Después de tantos años de esta peculiar situación relacional entre México y España, en la residencia oficial de Los Pinos parecía poco importar si el tiempo político español tras la muerte del dictador se leía en clave de República o Monarquía.

Regresando al informe enviado a Tlatelolco - sede en la Ciudad de México de la Secretaría de Relaciones Exteriores- desde la embajada mexicana en Madrid, Gómez Gordoa hizo una puntual y acertada reseña de los "antecedentes" de la situación política española del momento, en especial durante aquel 1977, año clave para el éxito final de aquella transición democrática. No obstante, su primera valoración no podía ser más alarmante. Dice así: "El tránsito de la dictadura a la democracia, manejada con una habilidad evidente por Su Majestad el Rey y Adolfo Suárez, ha pasado momentos dramáticos que quizás pusieron al país al borde de un golpe militar, especialmente al legalizarse el Partido Comunista y al aprobarse la Ley de Amnistía"15. Para añadir después: "La posibilidad de un golpe militar, en esos momentos, fue conjurada solamente por la esperanza de la monarquía, como la institución fundamental de este país"16.

En otro orden de cosas, Gómez Gordoa señaló con acierto que el proceso democrático español había tenido un "momento culminante", con motivo de la celebración de las elecciones generales del 15 de junio de 1977, donde salió ganador, y a la

13 Sola Ayape, 2008 y 2009.

14 De cualquier modo, también se pone de manifiesto el peso que México tenía en el imaginario político de algunas formaciones políticas del exilio, hasta el grado de convertirlo en un interlocutor válido ante el gobierno español, en ese entonces, liderado por un Adolfo Suárez que había sido nominado por el propio rey Juan Carlos. El juego político sólo estaba planteado para aquellas formaciones políticas -Partido Comunista de España, incluido-que aceptaban a la monarquía como forma de organización del Estado. Recordemos que, en aquellas primeras elecciones democráticas de junio de 1977, dos formaciones políticas se repartieron más de la mitad de la horquilla electoral: la Unión de Centro Democrático (34.44 \% de los votos) y el Partido Socialista Obrero Español (29.32\%).

15 La Ley de Amnistía, promulgada en España el 15 de octubre de 1977, supuso la amnistía de los presos políticos, así como de aquellas personas que habían cometido delitos vinculados con actos políticos, rebelión o sedición. $\mathrm{Su}$ objetivo no fue otro que contribuir, como medida legitimadora, a la consolidación del nuevo régimen por medio de la reconciliación nacional. Con respecto al delicado asunto de la legalización del Partido Comunista de España, he aquí las palabras de José María Areilza, quien fuera ministro de Asuntos Exteriores en el primer gobierno del rey Juan Carlos y cofundador de la Unión de Centro Democrático (UCD): "La debatida cuestión de legalizar al partido comunista era una de las claves de la tensión social. Fui siempre partidario de autorizar su incorporación activa a la vida pública en el futuro diseño institucional. Ello me valió insultos y amenazas violentas, en los mítines y reuniones, de lo que llamábamos el 'búnker'”. Areilza, 1992: 216.

16 A la muerte del general Franco, el proceso democratizador en España pasó por varios episodios estelares: primero, el referéndum sobre la reforma política (15 de diciembre de 1976); segundo, la aprobación de la Ley de Amnistía (17 de marzo de 1977); tercero, la legalización del Partido Comunista de España (9 de abril de 1977); cuarto, las primeras elecciones generales de la era posfranquista (15 de junio de 1977) y, finalmente, dos acontecimiento de los que daremos cuenta más adelante: la firma de los Pactos económicos de la Moncloa (27 de octubre de 1977) y la aprobación en referéndum de una nueva Constitución (6 de diciembre de 1978). 
postre nuevo presidente del Gobierno, el centrista Adolfo Suárez ${ }^{17}$. En esta ocasión, y a diferencia de su anterior nombramiento, su presidencia sí estaba legítimamente avalada por las urnas. Al margen de las muchas valoraciones que pudieran hacerse al respecto, es importante destacar que aquellas elecciones fueron un parteaguas en la memoria política de España al provocar la disolución definitiva de las instituciones de la República Española en el Exilio, cuya sede, como se ha dicho anteriormente, se encontraba en París desde 1946 en que se desplazaron a la capital francesa procedente de la Ciudad de México ${ }^{18}$.

A comienzos de 1977, Fernando Valera, en su condición de presidente del Consejo de Ministros de la República Española, había defendido la tesis de que el gobierno republicano en el exilio habría de seguir operativo hasta que el pueblo español -titular de la soberanía nacional- fuese llamado a urnas para la elección del nuevo presidente de Gobierno y el consiguiente reparto de escaños en el Congreso de los Diputados ${ }^{19}$. Después, y en la misma línea, José Maldonado, presidente de la República Española en el Exilio, recordó aquel 18 de marzo de 1977, día histórico porque México y la España republicana del exilio cancelaron sus relaciones diplomáticas, que:

las instituciones de la República Española proseguirán, como hasta ahora, luchando por el restablecimiento de la libertad y la democracia, hasta que el pueblo español, a quien compete con carácter exclusivo la concesión de la legitimidad del poder, haya podido establecer un nuevo régimen por medio de elecciones homologables como las que se celebran en los demás países de la Comunidad Europea, a la que España aspira a pertenecer ${ }^{20}$.

Fieles a la palabra dada, y una vez celebradas las mencionadas generales en España, desde París el 21 de junio de 1977 José Maldonado, en su calidad de presidente, y Fernando Valera, como máxima cabeza del Consejo de Ministros, firmaron la llamada Declaración de la Presidencia y del Gobierno de la República Española en el Exilio, un testimonio documental de alta significación histórica, donde, además de reafirmar la legalidad institucional republicana emanada de la Constitución de 1931 y ratificar la validez de los procesos electorales celebrados en 1931, 1933 y 1936, se hacía, primero, expreso reconocimiento de la nueva legitimidad nacida de las elecciones del 15 de junio; segundo, se aceptaban los resultados obtenidos en los comicios; y, finalmente, se daba a conocer de manera pública que "las Instituciones de la República en el Exilio ponen así término a la misión histórica que se habían impuesto", bajo el entendido de que "quienes las han mantenido hasta hoy se sienten satisfechos porque tienen la convicción de haber cumplido con su deber" ${ }^{\prime 21}$.

17 Compartimos la tesis de Charles Powell de que aquellas elecciones del 15 de junio de 1977 venían a significar la "superación oficial de las dos Españas". Powell, 2001: 194. Al respecto de la significación de aquellas primeras elecciones democráticas como "retorno a la democracia", véase Caciagli, 1986: 39-77.

18 Para una buena monografía sobre los pormenores de la reconstrucción en 1945 de las instituciones republicanas del exilio en la Ciudad de México, véase Serra - Mejía - Sola Ayape, 2014: 381.

19 Las declaraciones de Fernando Valera fueron reproducidas íntegramente en la prensa mexicana. Véase, por ejemplo, Últimas Noticias de Excélsior, 9-II-1977, 9.

20 Discurso de José Maldonado. Ciudad de México, 18-III-1977. AHGE, Expediente III-5251-1 (segunda parte).

21 La prensa española se refirió al acontecimiento en términos de "disolución" de la República Española en el Exilio. Véase, por ejemplo, Diario16, 21-VI-1977, 1 y La Vanguardia, 22-VI-1977, 3. 
Más allá de estas circunstancias que llevaron a la autodisolución de una de las Españas, lo cierto es que México y España -la monárquica, sobre el papel heredera del franquismo- abrazaron tiempos nuevos en la primavera de 1977, tiempos que, dicho sea de paso, fueron también de mucho realismo y pragmatismo políticos. No conviene olvidar que el México de López-Portillo se entregó al abrazo de una España -la juancarlista- que, si bien se encontraba en abierto proceso de transición democrática, todavía no había consumado sus dos grandes ritos legitimadores: sus primeras elecciones generales del 15 de junio de 1977 y su nueva Carta Magna del 6 de diciembre de 1978. Ambas fueron circunstancias que también se hicieron presentes en el marco contextual del establecimiento de las relaciones entre México y España el 28 de marzo de 1977, donde ambos países, eso sí, dieron por cerrado, y bien cerrado, el lacerante episodio de la Guerra Civil española.

En este contexto histórico de cierres y aperturas, hay que recordar que, con fecha de 13 de enero de 1977, la Dirección General del Servicio Diplomático mexicano había remitido un informe confidencial al presidente López-Portillo, intitulado "Normalización de relaciones con España", bajo el entendido de que "existe la decisión política tendiente a la normalización de relaciones diplomáticas entre México y España, y tomando en consideración que, hasta la fecha, el gobierno de México mantiene estos nexos con el régimen de la República Española en el Exilio". Así, se hacían dos importantes recomendaciones a la Presidencia de la República: la primera, "buscar cuidadosamente la fórmula que permita superar conveniente y satisfactoriamente el problema que representaría, llegado el momento, la suspensión de dichos nexos con la República española" y, la segunda, esperar hasta la celebración de las primeras elecciones democráticas en España y así encontrar "el argumento que conduce a la suspensión de relaciones diplomáticas entre México y la República española". Huelga decir que tras dicha suspensión quedaría expedito el camino para normalizar, y además de inmediato, las relaciones con la España juancarlista, una vez eliminada toda atadura con el pasado ${ }^{22}$.

A la postre, y lejos de atender a las recomendaciones de la cancillería, el presidente López-Portillo -por mandato constitucional, el máximo responsable de la política exterior mexicana- no quiso esperar al anunciado "punto de ruptura", sino que se anticipó a aquellas elecciones generales y además lo hizo con varios meses de antelación ${ }^{23}$. A decir verdad, y contra pronóstico, aquélla fue una decisión personal, marcada por principios de estricto pragmatismo político. Ya desde finales de 1976, José López-Portillo conocía las intenciones del gobierno de Suárez sobre las condiciones que debía reunir cualquier acercamiento diplomático entre ambos países. Con la muerte de Franco, se había eliminado al dictador; con las nuevas elecciones federales mexicanas de mediados de 1976, se había quitado de la escena política al presidente Luis Echeverría, quien intentó sacar a España de las Naciones Unidas a fines de septiembre de 1976 por los últimos fusilamientos del franquismo y que, por

22 Informe de la Dirección General del Servicio Diplomático mexicano remitido al presidente José López-Portillo. Ciudad de México, 13-I-1977. AHGE, Expediente III-5251-1 (segunda parte).

23 Uno de los principales críticos de la decisión prematura de normalizar las relaciones de México con la España monárquica fue precisamente Cuauhtémoc, hijo del ex presidente Lázaro Cárdenas. A su entender, las relaciones con España sólo significaban "una decisión del gobierno mexicano", ya que seguían prevaleciendo "las condiciones franquistas" que, en su día, habían obligado a su padre "a romper con España". Declaraciones de Cuauhtémoc Cárdenas recogidas en un informe elaborado por la Secretaría de Relaciones Exteriores de México. Ciudad de México, III-1977. AHGE, Expediente OEA-155-12. 
ende, fue considerado por la España franquista como persona non grata para protagonizar cualquier acercamiento diplomático. Sin embargo, y más allá de esta reunión de factores, aún faltaban por superar algunos escollos.

So pretexto de invitar personalmente a su toma de protesta a una delegación de Caparroso - pueblo de Navarra de donde salió en el siglo XVI Alonso López del Portillo hacia la Nueva España, para echar la raíz del árbol genealógico del nuevo presidente-, López-Portillo envió a Santiago Roel, su hombre de confianza en materia de política exterior y futuro canciller, para sondear la opinión de las autoridades españoles de cara a un inminente rencuentro diplomático. En los círculos internos de la cancillería mexicana, aquel viaje fue conocido como la "operación Caparroso", y sirvió para conocer las verdaderas pretensiones del gobierno español en su doble intención: primero, de hacer tabla rasa del pasado y, segundo, de buscar una fórmula de legitimidad para la monarquía española ${ }^{24}$.

Bajo estas premisas, México debía retirar su apoyo a la España republicana del exilio como conditio sine qua non para dar los pasos necesarios hacia una normalización del vínculo diplomático con la otra España, la del rey Juan Carlos. Por el contrario, España estaba dispuesta a aceptar la tesis mexicana de que México nunca había roto relaciones con España, bajo el entendido de que la España republicana había ostentado, a pesar de su exilio, la verdadera legitimidad democrática frente a la España franquista surgida de una revuelta armada -el alzamiento nacional de julio de 1936- y triunfadora en la Guerra Civil gracias al apoyo de las potencias nazifascistas. Nótese, al respecto, que las notas que los cancilleres de ambos países se intercambiaron en París el 28 de marzo de 1977, y con el que se daba por normalizado el vínculo diplomático entre nuestros dos países, se hablaba intencionalmente de "establecimiento" -y no de "restablecimiento"- de relaciones diplomáticas. De ahí que fuera España la que hiciera la petición de normalizar las relaciones y no al revés.

Para ese entonces, el principal problema que había que resolver era la eliminación de la España republicana del exilio del escenario de las negociaciones. Fiel al realismo y pragmatismo político de los líderes políticos en liza, el presidente LópezPortillo lo contaba con estas palabras, evocando lo acontecido en aquella tarde del 18 de marzo en la capital mexicana: "En la tarde, la dolorosa, tremenda, breve entrevista con el Presidente de la República Española en el Exilio, José Maldonado, para ratificar el acuerdo de suspender relaciones. El momento para mí fue dramático, emotivo. Pero tuve que tomar una decisión. Todo mundo quiere relaciones normales con España y pocos se daban cuenta de que la precondición era liquidar la relación con la República". Para añadir a continuación lo siguiente: "La República es ya un símbolo, ahora representado por un grupo cada vez más reducido de ancianos venerables que, desgraciadamente, no pueden ser razón que impida normalizar la relación. Si se cuestionaba la validez de un Gobierno en el exilio, ahora, que se abren las opciones democráticas en España, empezaba a ser caricatura"25.

En definitiva, la cancelación de las relaciones de México con la España del exilio devengó importantes dividendos políticos a la España juancarlista: primero, por su

\footnotetext{
Sola Ayape, 2015a.

25 El presidente López-Portillo llegó a añadir lo siguiente: “Al presentarse la decisión, la decisión en seco, la gente se impresionó y muchos cuestionan la medida. Imposible satisfacer a todos. Alguien tiene que tomar decisiones. Ésa es la función del Ejecutivo". En otra ocasión, hizo el siguiente comentario al respecto: "Me conmovió la comprensión, la inteligencia y la orgullosa humildad con la que los republicanos entendieron y aceptaron la decisión”. López-Portillo, 1988: 555 y 557.
} 
revés al activo político del republicanismo español; segundo, por el aval mexicano a la fórmula estatal de aquella transición de una dictadura a una democracia no en clave republicana, sino monárquica y, tercero, y a modo de síntesis, por la apuesta del México lópez-portillista por la España monárquica para asegurar la viabilidad y consolidación de la futura relación bilateral. Y esto así, a pesar de que el monarca, en su condición de jefe del Estado español, todavía no había tenido el refrendo del pueblo soberano, como sí lo tendría a raíz de la aprobación en las urnas de la Constitución española del 6 de diciembre de $1978^{26}$.

Al margen de estas singularidades del particular reencuentro entre México y la España "territorial" -adjetivación muy común al interior de la cancillería mexicana para referirse a la España monárquica frente a la otra del exilio-, el embajador mexicano Gómez Gordoa advirtió en su informe para el canciller Roel que España estaba inmersa en "un panorama confuso". Si bien el "partido dominante" en las Cortes era la Unión del Centro Democrático del presidente Adolfo Suárez ${ }^{27}$, lo cierto es que, en su entender, aquélla no era sino "una coalición de partidos centristas del que en los últimos momentos se pretende su unificación, desapareciendo sus integrantes, para hacer realmente un partido único" 28 .

Siguiendo con el arco parlamentario, pero con respecto a la oposición al Gobierno, Gómez Gordoa informaba que el Partido Socialista Obrero Español (PSOE) tenía el segundo lugar en el Congreso de los Diputados, bajo la dirección de Felipe González, significando que estaba "atenuando su imagen marxista para alinearse en la socialdemocracia, representada por el actual gobierno alemán (Willy Brandt)"29. En cuanto al Partido Comunista de España (PCE), de Santiago Carrillo, el embajador precisaba que su argumento discursivo venía sustentándose en el "eurocomunismo y su rompimiento con Moscú", con el fin de "introducirse en la opinión española y en la de los países occidentales". Finalmente, y con respecto al ala derecha, apuntaba al partido de Alianza Popular de Manuel Fraga Iribarne, haciendo énfasis en "el viraje

26 Años después, Adolfo Suárez dejó escritas estas palabras: "El Rey se convirtió en el punto de apoyo institucional imprescindible para llevar a cabo el cambio político y convertirse, al término del proceso, en Rey constitucional de todos los españoles". Suárez, 2002: 105.

27 La designación "real” de Adolfo Suárez como presidente del Gobierno español (3 de julio de 1976) representó un salto hacia adelante en aquel proceso democratizador con respecto a su predecesor al frente de la jefatura del Gobierno Carlos Arias Navarro. Ciertamente, y recuperando un testimonio de José María Areilza, "Arias no acababa de aceptar el hecho inevitable de la desaparición total del Estado franquista y de sus mecanismos de poder como cimiento indispensable de la Monarquía futura". Areilza, 1992: 216.

28 El presidente López-Portillo hizo su particular valoración sobre los principales líderes políticos españoles, con quien se entrevistó en su visita oficial a España en octubre de 1977: "Hablé con todos los dirigentes de los principales partidos: Felipe González, del Socialista, muy en la línea de Brandt, demasiado anticomunista, aunque con modelo de país y estrategia a largo plazo. Inteligente, joven, hábil. Puede llegar a formar gobierno si los conservadores se descuidan. Santiago Carrillo, del Comunista, muy europeo en sus planteos, también inteligente y capaz, eurocomunista, muy español, aparentemente poco ortodoxo. Tipo interesante. Fraga Iribarne, muy preparado. Tal vez el más experimentado. Abierto, a pesar de ser la derecha ostensible. Tipo interesante. Tierno Galván, intelectual español muy en la línea de los republicanos que conozco, aunque realista y objetivo. Tengo la impresión, sin embargo, que va a ser de los primeros desplazados". López-Portillo, 1988: 633.

29 El proceso de orientación política e ideológica del PSOE se inició ya desde su congreso de Suresnes -número 13 de los celebrados durante el exilio- entre los días 11 y 13 de octubre de 1974, esto es, antes de la transición democrática en España. Después, en su 28 congreso -Madrid, mayo de 1979-, el partido rechazó la pretensión de su secretario general -Felipe González- de retirar la definición marxista del PSOE. Tuvo que ser en su congreso extraordinario -Madrid, septiembre de 1979-, cuando el PSOE renunció definitivamente al marxismo como ideología oficial del partido, a pesar de mantenerla como instrumento crítico y teórico. A partir de entonces, el PSOE se definió como un partido socialista democrático y de organización federal. 
de la derecha al centroderecha, dialogando en una conferencia del Club Siglo XXI, que constituyó un golpe estratégico para colocar en el centro y mejorar imagen de agresividad" ${ }^{\prime 30}$.

En otro orden de cosas, Gómez Gordoa también hizo alusión a uno de los graves problemas que venía aquejando a la sociedad española durante aquellos primeros años de transición democrática. Así, y en palabras del embajador mexicano, "la situación económica continúa francamente mal, con un índice de inflación en el año de 1977 del $30 \%$ y un malestar por la carestía de la vida y el desempleo, a pesar de que la reserva monetaria ha aumentado en los últimos meses por un importante ingreso turístico" ${ }^{31}$. $\mathrm{Al}$ respecto, se hizo eco de una de las tesis del presidente Suárez, para quien resultaba "difícil gobernar un país, tanto en materia política como especialmente en materia económica, cuando se carece de un cuerpo de leyes que puedan ser aplicadas" ${ }^{\prime 32}$. En efecto, Gómez Gordoa señaló que España venía padeciendo dos graves problemas en este sentido: el primero, la ausencia de una Constitución -"la que se está elaborando por una comisión de todos los partidos"- y, el segundo, la imposibilidad "de dictar disposiciones con base legal para tomar medidas económicas y fiscales".

Con el fin de superar "ese vacío legal”, el embajador mexicano argumentó que el presidente Suárez -"en una situación paradójica"- había terminado por convocar a los jefes de los partidos importantes -"al margen del parlamento"- con el fin de votar "un plan económico y luego un plan político, a efectos de cubrir ese vacío legal. Es a dichos planes a lo que se ha dado en llamar el "Pacto de la Moncloa" [sic] ${ }^{33}$. Gómez Gordoa puntualizó que, "acto seguido", el presidente Suárez había sometido al parlamento "los citados planes" que, "al ser obviamente ratificados, han permitido iniciar el proceso legislativo para efectos de la toma de medidas de aplicación inmediata, con el propósito de combatir la inflación, crear empleos y aprobar una reforma fiscal, producto de un concienzudo estudio del equipo económico encabezado por el economista Fuentes Quintana"34. En este sentido, Gómez Gordoa acertaba a la hora

30 El 27 de octubre de 1977 el Club Siglo XXI invitó a Santiago Carrillo, líder del Partido Comunista de España (PCE), a pronunciar una conferencia. Para sorpresa de muchos, se contó para su presentación con la presencia de Manuel Fraga, líder de Alianza Popular (AP). Durante la celebración del acto, el abrazo que se dieron aquellos dos veteranos políticos fue concebido como un gesto sincero de superar las heridas que la guerra civil y la reconciliación de las dos Españas. Y esto a pesar de las airadas críticas que recibieron por parte de muchos afiliados de AP y del PCE. Durante su intervención, Carrillo dijo lo siguiente: "Somos conscientes de que el 15 de junio el país no votó por la transformación socialista de la sociedad, sino simplemente por el cambio democrático y respetamos fielmente el fallo popular". $A B C, 28-\mathrm{X}-1977,1$.

31 Sentida era la necesidad de corregir una aguda tasa de inflación, la progresiva caída de las inversiones con el consecuente y dañino impacto en las tasas de desempleo y, finalmente, el fuerte desequilibrio en la balanza comercial. Nadie dudaba en aquel entonces de que la credibilidad del tránsito de la dictadura a la democracia pasaba por mostrar y demostrar las bonanzas de una democracia en materia de bienestar social.

32 En una parte de su informe, Gómez Gordoa se hizo eco de la "visible preocupación" de los empresarios, especialmente por la peligrosidad que representaba el "deterioro en las inversiones". Informe de José Gómez Gordoa remitido a Santiago Roel. Madrid, 23-XI-1977. AHGE, Expediente III, núm. 3302-2.

33 En efecto, formalmente hablando, dos fueron los que se acabaron firmando: el primero, el acuerdo sobre el programa de saneamiento y reforma de la economía y, el segundo, un acuerdo sobre el programa de actuación jurídica y política. Ambos fueron firmados en el Palacio de la Moncloa el 25 de octubre de 1977.

34 No se oculta que, tras la coronación de Juan Carlos como nuevo rey, y la progresiva normalización de la vida política española, España vivió sus tres primeros años inmersa en un larvado proceso constituyente. Así, los Pactos de la Moncloa, de octubre de 1977, quedaron vinculados a la preparación, discusión y finalmente aprobación de la Constitución española de 1978. Como puntualizó el creador del borrador de aquellos pactos, el economista Enrique Fuentes Quintana, "la suerte de los Pactos estuvo asociada a la suerte de la Constitución". Fuentes, 1990: 34. El contenido completo de los Pactos de la Moncloa puede consultarse, entre otros, en Rubio, 1992: 473-487. 
de identificar los tres grandes fines de aquellos pactos firmados en la Moncloa: el primero, la consolidación democrática del actual régimen monárquico; el segundo, la superación de la crisis económica y, el tercero, la lucha contra la anarquía y el terrorismo.

A este respecto, es importante recordar que, con motivo de su viaje oficial a España, el propio presidente López-Portillo llegó a ser testigo excepcional de aquel proceso de discusión y negociación de estos pactos, que perseguían, como primera meta urgente, sacar al país de la grave crisis socio-económica en la que se encontraba sumida. He aquí las palabras del presidente mexicano:

Llegamos a España en plena crisis económica, con el gobierno Suárez empeñado en una sorda lucha negociada con todos los partidos políticos para sentar bases que den salidas. El momento de lo más interesante: tránsito político de la dictadura a la democracia por el camino de la monarquía y al tiempo resolver los problemas de la crisis económica. Dos cuestiones cada una de las cuales, aisladas, son pesadas y, juntas, casi imposibles. Pero parece que están logrando la salida ${ }^{35}$.

Su encuentro personal con muchos de los actores políticos y sindicales que hicieron posible la consumación de aquel ejercicio de consenso, le permitieron madurar un juicio propio sobre el significado y alcance de los mismos. En rueda de prensa, el presidente mexicano se expresó de esta manera sobre el proceso de negociación que culminó en los Pactos de la Moncloa:

Me ha impresionado el que se sumen en este momento dos problemas severos en España, y que se estén resolviendo con inteligencia y buena fe: de una parte, el tránsito político hacia la democracia, cuando todavía no hay una nueva Constitución, porque ésta se está votando, cuando todavía no hay instrumentos definitivos que puedan actuar del lado del gobierno, y que en estas condiciones se tenga que resolver una severa crisis económica ${ }^{36}$.

Y, en la misma dirección, el presidente mexicano volvió a comentar lo siguiente: "El pluralismo, que es esencia de la democracia, se expresa en España y tiene salidas tan constructivas como la reciente, que se llamó Pacto de la Moncloa, en que los partidos políticos, anticipándose a las decisiones de los factores económicos, coincidieron sus puntos de vista para resolver la crisis". Asimismo, López-Portillo resaltó otro de los asuntos importantes que estuvo presente en el proceso negociador de los Pactos de la Moncloa, a saber: "Todos los partidos políticos -y creo que ésta es la clave del asunto- han reconocido que, ahora y aquí en España, no hay más alternativa que seguir en una economía de mercado"37.

López-Portillo, 1988: 632.

Ibídem.

37 Presidencia de la República, 1977b: 132 y 144. También El País, 16-X-1977, 8. En palabras de Charles Powell, los acuerdos de la Moncloa representaron "una contribución crucial al éxito del proceso de transición. Ante todo, pusieron de manifiesto la existencia de un amplio consenso básico en torno a la economía social de mercado como futuro sistema socioeconómico". Powell, 2001: 208. 
El mandatario mexicano también llegó a hacer su particular semblanza comparativa entre lo que venía sucediendo en ese entonces en México y en España. He aquí sus palabras:

El momento es extraordinariamente parecido al nuestro, salvo que aquí partimos de la estabilidad política y actuamos directamente con los factores de la producción y tenemos petróleo. España no es un país en desarrollo; es un país desarrollado y si tuviera petróleo podría ser una potencia. Inflación, desempleo, balanza económica desfavorable, devaluación, son las expresiones que se leen en todos los diarios y en todos los $\operatorname{rostros}^{38}$.

En la línea de su presidente, y frente a la grave situación socio-económica de España y el recurso del pactismo para mitigar los efectos de la crisis ${ }^{39}$, el embajador Gómez Gordoa también señaló que la situación de España no había dejado de ser "confusa e inquietante", en su entender, porque la profundidad de la crisis económica hacía pensar que su superación, "en el mejor de los casos", habría tener "en un plazo no menor de 2 años" 40 . A su vez, ponía el acento en dos temas de especial calado: el terrorismo y la celebración de las próximas elecciones municipales. $\mathrm{Si}$, con respecto al primero, dijo que los actos de terrorismo habían disminuido, "pero no en forma total", con respecto al segundo objetó que las elecciones municipales, "recordando las del año de 1931, que derrocaron a la monarquía, eran una amenaza nuevamente a la propia estabilidad del rey Juan Carlos"41.

38 López-Portillo, 1988: 632. Algunos años después, y tras el histórico triunfo electoral del panista Vicente Fox en las presidenciales del 2 de julio de 2000, los Pactos de la Moncloa se presentaron en México como la panacea a seguir para apuntalar el éxito de aquella transición a la democracia. La experiencia pactista española fue un espejo donde se miró, principalmente, la presidencia de la República con el fin de apropiarse de una fórmula que fue presentada como una de las claves del éxito de la transición democrática española. A la postre, y frente a tantas expectativas levantadas, la mercadotecnia política estuvo muy por encima de las verdaderas intenciones de los actores políticos implicados. No se oculta que, a fecha de hoy, se sigue desconociendo si aquellos Pactos de Chapultepec, firmados en octubre de 2001, tuvieron alcance alguno. A este respecto, véase Sola Ayape, 2014.

39 Los firmantes de los Pactos de la Moncloa fueron los siguientes: Adolfo Suárez en nombre del Gobierno, Leopoldo Calvo-Sotelo (UCD), Felipe González (Partido Socialista Obrero Español), Santiago Carrillo (Partido Comunista de España), Enrique Tierno Galván (Partido Socialista Popular), Juan Ajuriaguerra (Partido Nacionalista Vasco), Joan Reventós (Convergencia Socialista de Cataluña), Josep Maria Triginer (Federación Catalana del PSOE) y Miquel Roca (Convergència i Unió). Cabe destacar que Manuel Fraga (Alianza Popular), si bien no firmó el acuerdo político, sí al menos ratificó el económico. Después, los acuerdos fueron ratificados en el Congreso y el Senado.

40 En palabras de Del Águila y Montoro, "si el consenso se utilizó como un argumento de fortalecimiento de la democracia y una cooperación en esa dirección, no cabe duda de que fue también a costa de que determinados temas [...] no fueran lanzados al tapete de la discusión política. En este sentido, el consenso no fue un argumento de diálogo y comunicación, sino justamente lo contrario: un argumento silenciador”. Del Águila - Montoro, 1984: 131 y 132.

41 En aquellas elecciones municipales, celebradas el 3 de abril de 1979, donde llegaron a participar 101 formaciones políticas, la UCD logró la victoria en los comicios con 28.960 concejales y un apoyo del 30,6\% del electorado; en segundo lugar quedó el PSOE con 12.077 concejales y un respaldo del 28,2\% de los votos y, finalmente, el PCE conquistó la tercera plaza con 3.732 concejales y el 13,1\% de los sufragios emitidos. Como puso de manifiesto Lourdes López, esta proliferación de partidos políticos se explica por uno de los rasgos que definió al franquismo durante largos años: "el carácter personalista en las relaciones políticas". Con las primeras elecciones -generales y municipales- de la democracia española la aparición de tantos "grupos creados en torno a personajes fueron eliminados del juego político", clarificando posteriormente el panorama electoral. López, 1992: 85 . 
No le faltaba razón a Gómez Gordoa al recordar la trascendencia histórica de aquellas elecciones municipales de abril de 1931 que, entre otras múltiples consecuencias, acabó con el reinado de Alfonso XIII y dejó expedito el camino para el advenimiento de la Segunda República. Sin embargo, a estas alturas de los años setenta, las primeras elecciones municipales de la recién recuperada democracia española, que, dicho sea de paso, se celebraron un año y medio después del presente informe de Gómez Gordoa, se encontraban en un marco histórico de aristas muy distintas. Aquellas municipales de abril del 79 nunca tuvieron un carácter plebiscitario sobre el modelo de Estado, principalmente, porque para entonces España ya se había dado un nueva Constitución, refrendada por el pueblo español en referéndum del 6 de diciembre de 1978.

Baste recordar que en su artículo primero quedaba estipulado que la soberanía nacional residía en el pueblo español, "del que emanan los poderes del Estado", y que la forma política del Estado español es la "Monarquía parlamentaria". Precisamente, la concreción del nuevo modelo de Estado español quedó recogida en el título II ("De la Corona") del texto constitucional. Así, y por el artículo 56, "el Rey es el Jefe del Estado, símbolo de su unidad y permanencia, arbitra y modera el funcionamiento regular de las instituciones, asume la más alta representación del Estado español en las relaciones internacionales, especialmente con las naciones de su comunidad histórica". A su vez, al rey le corresponde, entre sus múltiples funciones, "sancionar y promulgar las leyes" y "el mando supremo de las Fuerzas Armadas" (art. 62).

Dicho de otra forma, y mediante el concurso del titular de la soberanía nacional, la Constitución española había refrendado, entre otros múltiples aspectos, no sólo el nuevo modelo de Estado, sino que dotaba a la figura del monarca de una autoridad y legitimidad de la que para amplios sectores de la sociedad española carecía hasta ese entonces, desde el momento en que su coronación había tenido lugar al amparo de las leyes del Movimiento Nacional (franquista) ${ }^{42}$. De ahí que el verdadero éxito, y esto no conviene olvidarlo, de los Pactos de la Moncloa fuese la gestación de un escenario de certidumbre ante la colaboración decidida de las partes para lograr acuerdos en beneficio del común. En riesgo estaba el futuro de aquel embrión democrático, que tantas dudas había despertado en su origen por la decisión del dictador de convertir al príncipe Juan Carlos en su sucesor al frente de la jefatura del Estado.

Siguiendo con el informe de Gómez Gordoa, y "en estas circunstancias" reseñadas, el titular de la embajada de México en España también quiso subrayar que últimamente el "juego político" en España se venía agudizando a través de los "siguientes actos": en primer lugar, las entrevistas del líder socialista Felipe González con el presidente Suárez y el rey Juan Carlos, y su posterior viaje a los Estados Unidos "para presentarse como la alternativa de poder, en una crisis del gobierno de centro de Adolfo Suárez" ${ }^{3}$. En segundo lugar, la presencia del líder comunista San-

42 "No sé hasta qué punto estas leyes que he de jurar hacen inviable la Constitución democrática del futuro", llegó a confesar el propio príncipe fechas antes de su coronación. Seco, 2002: 59. Además, hay otro factor de peso que tiene que ver con la presencia de un imaginario colectivo que tuvo muy presente la memoria histórica heredada del pasado. Como puso de manifiesto Colomer, "la obsesión de una gran mayoría de la población y de los líderes sociales y políticos en la segunda mitad de los años setenta era, en contraste con épocas históricas anteriores, evitar una nueva guerra civil. [...] Es, pues, la existencia de enfrentamiento civil y su memoria lo que determina conductas que buscan evitar su repetición". Colomer, 1998: 40.

43 El propio Felipe González reconoció que su viaje a los Estados Unidos habría de contribuir a la consolidación de la democracia en España. $A B C, 16-X I-1977,19$. 
tiago Carrillo, predicando "la tolerancia" y coincidiendo con Felipe González en la aceptación del "régimen monárquico como la tabla de salvación de la democracia"44 y, por último, la presión que Felipe González venía recibiendo de los partidos socialistas en el poder -Inglaterra, Alemania Federal y "otros países europeos de menor importancia"- para "cambiar su postura socialista a las características de la socialdemocracia no marxista".

Ante la concurrencia de estas condiciones, para Gómez Gordoa España era un "hervidero político", especialmente, "pensando en la posibilidad de que se establezca en breve plazo un gobierno de coalición de centro-izquierda, en el que Felipe González, eventualmente, pueda ser vicepresidente del Gobierno, con varias carteras". Por eso, el embajador mexicano señalaba que, si bien no había "criterio definido", sería fundamental "en los próximos meses la acción de Adolfo Suárez, con el apoyo real, la que decida el futuro inmediato de España".

En otro orden de cosas, el embajador mexicano también hizo especial alusión a la situación internacional que se vivía en el marco de la Guerra Fría. Para el titular de la embajada mexicana, en el "trasfondo de toda esta situación", era evidente que los Estados Unidos (Jimmy Carter) y Alemania Federal (Helmut Schmidt) estaban "influyendo decididamente en el porvenir de España", especialmente, porque se venía considerando que España debía entrar la OTAN, "aun cuando por otra parte la Europa de la Comunidad sigue reacia a su ingreso inmediato". Así, y en palabras de Gómez Gordoa, "el futuro cuadrilátero -Washington, Bonn, Madrid y Tel Aviv-, es la meta del mundo occidental, manejado por los Estados Unidos y a ello se opone radicalmente la política soviética".

Para la finalización de su informe, y a modo de conclusión final, Gómez Gordoa no ocultó su sentida preocupación por el futuro político del país que estaba conociendo desde su condición de embajador. "La democracia está en juego en España -escribió- y sólo la participación de las fuerzas del centro-derecha y del centro-izquierda podrá realizar el milagro". Para lograr tal fin, visualizaba "dos rutas previsibles": la primera, la consolidación de la Unión de Centro Democrático de Adolfo Suárez, "si logra controlar las elecciones municipales, cuya fecha es imprecisa, pero que podrá acontecer quizás para la próxima primavera" $\mathrm{y}$, la segunda, la alternativa de poder, "más amenazante y quizás menos riesgosa para monarquía, si se llega a un entendimiento entre Suárez y Felipe González para compartir el poder, a pesar de las declaraciones de éste, últimamente, de que sólo lo tomará en forma total" ${ }^{\prime 4}$.

\section{México ante la política exterior española hacia América Latina}

Como era de esperar, la nueva política exterior de aquella España en transición hacia la democracia fue uno de los grandes puntos de interés para un país como México, especialmente, en todo lo concerniente con la relación bilateral y, en general, con el área de América Latina. Una vez establecidas las relaciones diplomáticas en marzo de 1977, el buen momento de entendimiento entre las partes se tradujo en la celebración de los primeros viajes oficiales, primero, del presidente español Adolfo Suárez

44 Sobre el giro político del Partido Comunista de Santiago Carrillo, véase Sánchez Biosca, 2016.

45 Informe de José Gómez Gordoa remitido a Santiago Roel. Madrid, 23-XI-1977. AHGE, Expediente III, núm. $3302-2$. 
y, meses después, del presidente mexicano José López-Portillo, ambos en abril y octubre de 1977 respectivamente. En noviembre del año siguiente, sería el rey de España el encargado en visitar México ${ }^{46}$.

Para ello, nos valdremos de una fuente primaria de primera mano, concienzudamente elaborada desde las dependencias de la Secretaría de Relaciones Exteriores de México, en el marco de la preparación del viaje oficial del presidente LópezPortillo a España, que finalmente tuvo lugar del 8 al 16 de octubre de aquel 1977. Concebido para su uso interno, este compendio de documentación mecanografiada recibió el nombre de la "carpeta operativa", que se tradujo en un largo y detallado informe confidencial en torno a un amplio repertorio de temas vinculados con España -políticos, sociales, económicos, culturales, etcétera-, destacando sobremanera el capítulo de las relaciones hispano-mexicanas y, en general, sobre el modo en que España pretendía relacionarse con el mundo y, específicamente, con la comunidad de países latinoamericanos. De hecho, no fue casual que uno de los grandes apartados temáticos fuera intitulado "Política Exterior de España"47. Si bien se trata de una fuente documental anónima, por no llevar firma ni marca alguna de identificación, la lectura del expediente nos lleva a la conclusión de que la autoría intelectual fue compartida y que uno de sus responsables fue precisamente el mencionado embajador José Gómez Gordoa ${ }^{48}$.

Como era previsible, aquella España en franca transición hacia la democracia estaba obligada a dotar de un nuevo carácter a su política exterior, acorde con las necesidades y hasta requerimientos del momento, sustentado en principios democráticos y especialmente cuidadosos con el Derecho Internacional, desterrando, por consiguiente, los atributos característicos que durante 40 años fueron definiendo la particular manera con la que el régimen franquista se fue relacionando con el mundo, especialmente, con la América hispana. Sobre el papel, el paternalismo y la propensión a la tutela debían dar paso a una relación sustentada en términos de reciprocidad, respeto e igualdad soberana.

Para cuando el presidente López-Portillo emprendió su viaje oficial a España en octubre de 1977, habían transcurrido prácticamente dos años desde la coronación de Juan Carlos como rey de España y, a la postre, de su asunción como nuevo jefe del Estado español y máximo responsable de la política exterior. Por tanto, y para entonces, ya eran conocidos los principios rectores que habrían de vertebrar la nueva política exterior española. De hecho, las primeras visitas oficiales de los reyes de España a América -República Dominicana (31 de mayo-1 de junio de 1976) y Colombia (11-14 de octubre de 1976- advertían claramente de las intenciones españolas con respecto a su relación presente y futura con los países de la América hispana. En esencia, la arquitectura discursiva del nuevo monarca se venía basando en cuatro raí-

46 Sobre los viajes del rey Juan Carlos I a México, véase Sola Ayape, 2018.

47 Carpeta operativa elaborada por la Secretaría de Relaciones Exteriores de México con motivo de la preparación del viaje oficial del presidente López-Portillo a España. Ciudad de México, X-1977. Archivo General de la Nación [México], fondo Presidencia de la República, presidente José López Portillo, serie Secretaría de Relaciones Exteriores, caja 2345, expediente 37414 (España). Tratándose de un gran expediente sin foliar, los entrecomillados que se irán mostrando están sacados de esta fuente documental primaria, advirtiendo oportunamente cuando la información utilizada se obtenga de otras procedencias, bien documentales, bien bibliográficas.

48 El 27 de diciembre de 1977, el presidente López-Portillo escribió en su diario personal unas notas que después publicaría en una de sus obras: "Vino también Gómez Gordoa. Lo siento con ganas de regresarse de España, una vez que pasaron las hazañas diplomáticas de la reanudación de relaciones. Voy a ver si lo aprovecho aquí. Se lo ofrecí". López-Portillo, 1988: 668. 
ces comunes -historia, lengua, cultura y religión-, en tres ideales básicos -libertad, justicia y paz- y en la concepción de un proyecto político de largo plazo, basado en el respecto a los derechos humanos y al Estado social de Derecho, que giraría en torno a futuras realizaciones de unidad y comunidad, como esa pretendida Comunidad Iberoamericana de Naciones ${ }^{49}$.

Por tratarse de un asunto de especial relevancia, éste fue otro de los rubros donde se puso especial acento en el informe que dio cuerpo a la carpeta operativa del viaje presidencial a España ${ }^{50}$. De entrada, en el mismo se hacía hincapié en el hecho de que las "líneas generales" de la nueva política exterior española habían sido tomadas del programa electoral de aquella coalición de formaciones políticas que era la Unión de Centro Democrático (UCD) y que, de manera estratégica, seguían la orientación de dos vectores por excelencia: el primero, "la posición geográfica, las condiciones físicas y las económicas" de España y, el segundo, "la historia, la tradición cultural y la voluntad democrática del pueblo español".

Partiendo de estas directrices, se hacía la puntual observación de que era manifiesta la tendencia de aquella España nueva por salir de su aislamiento e incorporarse a la comunidad internacional, "revitalizando su capacidad de acción [e] incrementando su nivel de influencia de intervención". Así, de esta primera valoración se desprendía la idea de que, tanto por sus circunstancias histórico-geográficas, como por su voluntad expresada de "acrecentar su influencia de intervención", la nueva política exterior española estaba siendo enfocada "a los países en vías de desarrollo, especialmente los de ascendencia hispánica".

Por tanto, y sobre esta línea de acción revitalizadora, la UCD había concebido su programa de gobierno desde tres prioridades regionales $-\mathrm{y}$ además por este orden- para dar cuerpo y sentido a la nueva política exterior española: Occidente, Iberoamérica y el Mediterráneo ${ }^{51}$. No hay que olvidar que esta vocación de origen quedaría poco después plasmada en el preámbulo de la Constitución española del 6 de diciembre de 1978, donde de manera explícita se hacía confesión de la voluntad de España por "colaborar en el fortalecimiento de unas relaciones pacíficas y de eficaz cooperación entre todos los pueblos de la Tierra".

Mientras que Occidente significaba "la urgencia económica de España para su integración a la CEE [Comunidad Económica Europea]", así como el mantenimiento de los "vínculos de cooperación" con los Estados Unidos, por el contrario, y en el caso del Mediterráneo, el interés principal estaba orientado hacia el Magreb, "en los cuales la tecnología y los productos españoles tienen un campo muy propicio, ante la riqueza petrolífera de algunos de esos países y las carencias productivas de todos ellos". Además, tal y como se señalaba, tradicionalmente España había mantenido relaciones muy estrechas y amistosas con éstos, "aduciendo nexos históricos y raciales muy discutibles".

No obstante, y para el caso que nos ocupa, no hay duda de que España tenía un especial interés estratégico por Iberoamérica, hasta el punto de que el gobierno de

49 Galvani, 1987: 11.

50 Concebido de manera confidencial y para uso interno, este expediente oficial es una prospección analítica del statu quo de aquella relación bilateral entre México y España, así como un diagnóstico de su potencial multisectorial en múltiples aspectos políticos, económicos, comerciales, etcétera. Se trata, por tanto, de una mirada analítica -cuantitativa y cualitativa, descriptiva e interpretativa-, donde no faltan las recomendaciones sobre las ventajas y desventajas de la nueva relación diplomática.

51 Sobre los fundamentos de aquella política exterior española, véase, a modo de ejemplo, Del Arenal, 1992. 
Suárez llegó a visualizar tres importantes ejes de acción, tal y como se advierte en el informe elaborado desde Tlatelolco: primero, la gestación de una Comunidad Hispánica de Naciones; segundo, la creación de un "puente" entre España e Iberoamérica; y, por último, el inicio de un proceso abierto de "integración" conjunta, donde España anhelaba jugar "el rol de promotor de la integración económica y comercial de Iberoamérica". De hecho, la idea de convertir las relaciones bilaterales entre México y España, así como en el resto de los países latinoamericanos, en un puente entre ambas orillas del Atlántico ha venido siendo utilizada, una y otra vez, cuando se ha tratado de encajar la palabra "España" en un rompecabezas formado por dos antípodas: América y Europa ${ }^{52}$. La última, y muy reciente, cuando el 7 de febrero de 2017 el presidente del gobierno español Mariano Rajoy le ofreció al presidente estadounidense Donald Trump ser interlocutor con la Unión Europea y Latinoamérica.

De este modo, y según el parecer de la cancillería mexicana, la naturaleza de esta acción dirigida hacia el escenario internacional era el resultado del "retraso que tiene España en la configuración de una estructura económica en el exterior que permita, por una parte, asegurarse nuevos mercados y consolidar los existentes y, por la otra, garantizarse el suministro de materias primas y mano de obra barata para sus necesidades industriales a medio y largo plazo, respectivamente". Y para lograr tales propósitos, y como primer objetivo de corto plazo, la estrategia de aquella España del rey Juan Carlos pasaba, primero, por el "abandono de la postura franquista, que tendía al paternalismo cultural y al imperio económico de España en América hispánica” y, segundo, por una definición "más pragmática en función de las necesidades económicas y políticas del país".

Ciertamente, el contenido del informe de la carpeta operativa se hacía eco de la tradicional idea franquista de "imperio", concebida ésta como "un concepto paternalista sobre las antiguas colonias españolas", que "bloqueó en muchos sentidos una política exterior sana con Iberoamérica" ${ }^{53}$. Recordemos que el discurso político del franquismo, de manera muy marcada durante su primera etapa hasta 1945 , se nutrió estratégicamente del ideario político del líder falangista José Antonio Primo de Rivera. De hecho, los tres primeros puntos del credo del nacionalsindicalismo de Falange Española respondían al tridente conceptual "Nación-Unidad-Imperio". Desde una concepción casi dogmática, se llegó a creer en la "suprema realidad de España", en la "unidad de destino en lo universal" y, por último, en la "voluntad de Imperio" "54. Descartadas, por desproporcionadas e inverosímiles, otras vías de intervención como la armada, el proceso de penetración del franquismo en los países de la América hispana acabaría siendo -como éxito disparejo según los países- por la vía de la propaganda y la acción cultural. A la postre, la gestación de un "imperio de papel", en palabras de Lorenzo Delgado Gómez-Escalonilla ${ }^{55}$, se convirtió en la

52 Sola Ayape, 2010b: 10. Al respecto de la metáfora "puente" como elemento toral de la narrativa discursiva de aquella política exterior, he aquí el siguiente testimonio de Fernando Morán: "El estilo muere más lentamente que la ideología y una de las palabras que nos traen remembranzas del pasado es la de puente: España puente entre Europa y América; puente de culturas, encrucijada de culturas y civilizaciones; España, como vehículo, lo sería todo o no sería nada". Morán, 1980: 399. Así, y en palabras de Roberto Mesa "es triste constatar que tanto la izquierda como la derecha [españolas] aún no han superado el estado freudiano materno-filial: España, portavoz; España, puente". Mesa, 1988: 46.

53 Como acertadamente señaló Rosa Pardo, "el nacionalismo español contemporáneo había dejado que América se incorporase a la mitología histórica patria”. Pardo Sanz, 1995: 31.

54 Primo de Rivera, 1941.

55 Véase Delgado Gómez-Escalonilla, 1988 y 1992. 
estrategia más eficaz para modelar el pretendido imaginario hispano-americano a través de la idea de la hispanidad. Para Ramiro de Maeztu, y frente a la doble acechanza ideológica -el comunismo soviético y el liberalismo materialista-, los países hispanoamericanos debían cultivar "los principios comunes de la Hispanidad"s6.

Ante estas circunstancias, y con el fin de superar los resabios del pasado franquista, la cancillería mexicana señalaba que España venía afrontando una "nueva época" y que el gobierno español había delineado "una nueva política de acercamiento y cooperación con los países hispano-americanos", asentándose no sólo en "los principios históricos-culturales tradicionales, sino además en la necesidad económica que tiene España de buscar nuevos mercados para su producción y fuentes de abastecimiento para sus requerimientos de materias primas". De cualquier manera, y así se hacía explícito, el gobierno de Suárez no había desarrollado hasta entonces "ninguna estrategia de penetración económica que le garantice suministros y mercados", salvo la creación del Centro Iberoamericano de Cooperación, "que propende a la expansión económica de España en los países latinoamericanos" $"$. En palabras de Celestino del Arenal, por primera vez en muchas décadas España estaba en condiciones de tener una "presencia solidaria en Iberoamérica, alejada de los intereses hegemónicos o paternalistas que habían caracterizado épocas anteriores" 58 . Dicho de otro modo, y recuperando un testimonio de Fernando Morán, toda propuesta de acción debía superar "la imputación de irrealista, ideologizada y desproporcionada"59.

A este respecto, resulta pertinente recuperar unas declaraciones de Marcelino Oreja Aguirre, en ese entonces titular del Ministerio de Asuntos Exteriores español. En primer lugar, las pronunciadas a fines de 1976, cuando confesó que España ya estaba en condiciones de formular una política exterior con respecto a Iberoamérica, "erigida sobre unos principios rectores claros y conocidos, que tengan el efecto de proyectar, en lo sucesivo, una luz diáfana y sin equívocos sobre las decisiones y su porqué" ${ }^{60}$. Meses después, y una vez restañado el vínculo diplomático hispanomexicano, Oreja se pronunció en estos términos: "Una vez normalizadas las relaciones con México, nos preocupamos en el Ministerio por dotarnos de un cuerpo de doctrina sobre lo que debía ser nuestra futura política con Iberoamérica [...] y que sirvieron de referencia en los discursos oficiales de aquellos años"61. En esencia, aquel cuerpo doctrinario descansaba sobre estos cinco principios rectores:

56 Maeztu, 1934: 298. En diciembre de 1931, meses después del triunfo de la Segunda República española y el consiguiente ocaso de la monarquía borbónica, Ramiro de Maeztu hizo esta interpretación de la hispanidad y, en consecuencia, cuál debía ser el destino de los pueblos americanos: "Percibimos el espíritu de la hispanidad como una luz de lo alto. Desunidos, dispersos, nos damos cuenta de que la libertad no ha sido, ni puede ser, lazo de unión. Los pueblos no se unen en libertad, sino en la comunidad. Nuestra comunidad no es geográfica, sino espiritual. Es en el espíritu donde hallamos al mismo tiempo la comunidad y el ideal". Maeztu, 1931.

57 El precedente del Centro Iberoamericano de Cooperación había sido el Instituto de Cultura Hispánica -institución creada en diciembre de 1945 fruto de la reconversión del Consejo de la Hispanidad fundado en noviembre de 1940, en un contexto histórico marcado por el aislamiento que sufrió la España franquista por parte de la comunidad internacional vencedora en la Segunda Guerra Mundial- con el fin de preservar el ideario de la cultura hispánica. En 1979, y dependiente del Ministerio de Asuntos Exteriores español, se creó en Madrid el Instituto de Cooperación Iberoamericana (ICI), una institución que venía a nutrir todo vínculo de España con la comunidad de países iberoamericanos. La estrategia de aquella España en proceso de democratización pasaba por fortalecer la "cooperación" entre iguales con los países americanos, especialmente, de habla hispana.

58 Del Arenal, 1994: 9.

59 Morán, 1990: 86.

60 El País, 21-XII-1976.

61 Oreja, 2002: 186. 
1. Principio de indivisibilidad: Las relaciones debían integrar todos aquellos aspectos de interés bilateral sin menospreciar ninguno de ellos, por ejemplo, el plano económico con respecto al cultural.

2. Principio de credibilidad: Cualquier iniciativa entre las partes debía hacerse de manera realista, es decir, evitando las "fantasías imposibles".

3. Principio de continuidad: Había que priorizar las acciones de medio y largo plazo, preservando en todo momento el compromiso entre las partes para la consecución de los logros previstos.

4. Principio de indiscriminación: Se hacía imperativo salvaguardar la hermandad por encima de cualquier posible disputa, y para ello la Doctrina Estrada debía ser el marco referencial, ya que "los enjuiciamientos entre hermanos no deben empañar la convivencia" ${ }^{\prime 2}$.

5. Principio de comunidad: Toda estrategia común debía inspirarse en una idea comunitaria, fruto del anhelo de preservar la cohesión del grupo y un espíritu solidario compartido ${ }^{63}$.

$\mathrm{Y}$, sin embargo, y frente a los buenos propósitos, en el informe de cancillería se recordaba que los nexos históricos y culturales de España con los países latinoamericanos no siempre habían tenido "relaciones económicas y políticas especiales", ya que la influencia que más había acercado económicamente a España con Latinoamérica había sido la ejercida por "los emigrantes españoles establecidos en la región, que han propiciado un vínculo directo para las transacciones comerciales y para el desarrollo de la cooperación económica". Anteriormente, "la única acción coherente de orden multilateral" que ejercía España en el bloque latinoamericano era la que desarrollaba el Instituto de Cultura Hispánica, dependiente del Ministerio de Asuntos Exteriores, y referida exclusivamente "al terreno cultural e histórico, mediante el intercambio de becarios y el auspicio de investigaciones y ediciones conjuntas".

En consecuencia, la nueva política hacia Iberoamérica venía registrando un primer esfuerzo por "la penetración discreta de Latinoamérica", sin afectar con ello a "los intereses norteamericanos en la región, ni plantear un conflicto entre la necesidad de acercamiento con los países de habla hispana de América y los valores entendidos que conlleva el Tratado de Amistad con los Estados Unidos" ${ }^{94}$. De cualquier modo, y más allá de los intereses comerciales en la región, se decía también que los grupos de oposición al gobierno de Suárez habían manifestado la necesidad de consagrar unas relaciones con América Latina desde los principios democráticos

62 La Doctrina Estrada es el principio toral de la política exterior de México desde 1930. Creada por el entonces secretario de Relaciones Exteriores, Genaro Estrada, durante la presidencia de Pascual Ortiz Rubio, esta doctrina se posicionaba en contra de que los países decidiesen si un gobierno extranjero era legítimo o ilegítimo, especialmente si este provenía de movimientos revolucionarios. Por consiguiente, se contravenía la costumbre de la época de que cada país debía reconocer al gobierno de otro país para que este fuera considerado válido o legítimo.

63 El 25 de abril de 1977, y en su visita oficial a México, el presidente Suárez hizo exposición de estos principios con motivo del brindis de honor ofrecido por el presidente López-Portillo en la Plaza de las Tres Culturas. Véase Presidencia de la República, 1977a: 72.

64 El 6 de noviembre de 1976 entró en vigor el Instrumento de Ratificación de España del Tratado de Amistad y Cooperación entre España y los Estados Unidos de América. Véase en Boletín Oficial del Estado, núm. 267, 6-XI-1976, 21911-21941. Al respecto, y como señaló Celestino del Arenal, el cauce de estas negociaciones entre España y los Estados Unidos estuvo condicionado por el éxito político de la transición democrática y por una futura integración de España en la Alianza Atlántica. Del Arenal, 2011: 189. 
y "las justas causas de la región que lucha por su independencia económica y su desarrollo". En concreto, partidos como el PSOE venían insistiendo en la necesidad de superar conceptos tan arcaicos como "Hispanidad" o "Madre Patria", a la vez que solicitaban una ayuda decidida y necesaria para aquellos pueblos "cuyos derechos humanos están siendo violados" en países como Chile [de Pinochet], Argentina, Paraguay y Uruguay y, más en concreto, "una visión de censura en Naciones Unidas para el primero".

En este sentido, la Secretaría de Relaciones Exteriores señaló un aspecto de crucial importancia en el mencionado informe de la carpeta operativa: "los aspectos que interesaban a México en su relación con España". Específicamente en el ámbito de las relaciones bilaterales, y si bien se reconocía el acierto de "la reconstitución de las relaciones de vínculos estrechos en el plano político"-recordemos, el canje de notas comentado del 28 de marzo de 1977 entre los cancilleres Santiago Roel y Marcelino Oreja- ${ }^{65}$, se hacía sin embargo el señalamiento explícito de que dicha relación debía darse "sobre bases de igualdad, desterrando toda idea de neocolonialismo por parte de España hacia los países de América Latina". Así, el realce de esta idea se hacía bajo el entendido de que "en múltiples ocasiones el rey Juan Carlos, al referirse a las relaciones entre su país y los nuestros", había afirmado que la Corona, "al asumir el legado histórico que da origen a la comunidad de pueblos iberoamericanos, y dada la proyección de la constante política exterior española -hecho bajo un signo de modernidad que el espíritu y las necesidades del día exigen-, ha iniciado una nueva era de dichas relaciones". Por eso, la cancillería mexicana hacía la recomendación expresa de que, una vez que la delegación presidencial estuviese de visita oficial en España, se preguntase "a los responsables de la política exterior española en qué consiste tal concepto o qué define esa nueva era".

Así con México, así con el resto de los países de América Latina, donde la participación española en la región debía estar "concebida en términos de absoluta igualdad y respeto hacia todos y cada uno de los países latinoamericanos". Esta advertencia no era gratuita. Una vez recuperado el vínculo diplomático entre México y España, los primeros encuentros oficiales entre las partes fueron utilizados por parte de México para hacer un especial énfasis en la idea de anteponer por encima de todo el respeto mutuo, la salvaguarda de la soberanía nacional y la preservación del principio de no intervención, todos ellos principios deudores del viejo credo que nutrió el discurso del régimen presidencialista mexicano que salió de la Revolución: el nacionalismo revolucionario ${ }^{66}$.

Por su parte, cancillería hacía dos recomendaciones estratégicas, pensando en el futuro rol que México debía asumir a la hora de contribuir al fortalecimiento de los vínculos de España con la región latinoamericana. En primer lugar, y dado "el insuficiente conocimiento de España sobre América Latina, obligará a México a puntualizar numerosos y variados aspectos de la problemática social, política y económica de los países latinoamericanos con objeto de que no sufran distorsión los

65 El periódico oficial del aquel régimen presidencialista mexicano consideró la reanudación de las relaciones hispano-mexicanas como un acontecimiento de "gran resonancia histórica". El Nacional, 30-III-1977, 1.

${ }_{66}$ Como señaló Mario Ojeda, México definió su política exterior durante el siglo XX asumiendo su condición de "país débil" y, por consiguiente, concibiendo su corpus de doctrina desde la "defensa de los intereses nacionales internos" y, por tanto, desde "la preservación y afirmación de la soberanía nacional”. Ojeda, 2001: 9. Acerca del nacionalismo revolucionario y la doctrina internacional de la Revolución Mexicana, véase Gómez Villanueva, 2010 . 
enfoques españoles sobre la región"67. En segundo término, se hacía la sugerencia de que la visita del presidente López-Portillo a España fuera el inicio de "un sistema de consultas periódicas" encaminadas a la "concertación de posiciones comunes sobre problemas internacionales concretos", poniendo énfasis en que dichas consultas serían con el propósito de "analizar los puntos de coincidencia antes de tomar decisiones". Con este último apunte, se vislumbraba en el horizonte de las relaciones diplomáticas la necesidad de tener encuentros periódicos para concretar una agenda conjunta. Se anunciaban, en consecuencia, las Cumbres Iberoamericanas de Jefes de Estado y de Gobierno, siendo la primera en julio de 1991 en la ciudad mexicana de Guadalajara y la segunda en Madrid en julio del año siguiente.

Lo cierto es que, días antes de su viaje oficial a España en octubre de 1977, el presidente López-Portillo recibió un informe desde la Secretaría de Relaciones Exteriores, con el fin de señalar los temas que "podrían suscitarse en el curso de las entrevistas" con el rey Juan Carlos y el presidente Suárez. En el mismo, se hacían dos señalamientos de suma importancia: en primer lugar, la cancillería identificaba la necesidad de fortalecer una estrecha colaboración entre México y España para "fortalecer la unidad latinoamericana y trabajar en pro de la consolidación de los lazos" y, en segundo término, la pertinencia de visualizar un triángulo entre Europa y América Latina, pasando por España: "Es de esperarse que si España es admitida en la Comunidad Económica Europea pueda llegar a convertirse en un vocero autorizado para plantear los términos de una nueva relación entre Europa y América Latina" ${ }^{68}$.

\section{Valoraciones finales}

A tenor de lo expuesto más arriba, una de las principales valoraciones que se desprenden del análisis del contenido de las fuentes documentales seleccionadas es el puntual seguimiento que México hizo de la evolución de la vida política española durante los primeros compases de la transición democrática. A decir verdad, los responsables de la política exterior mexicana entendieron como pocos que el proyecto de vinculación de aquella España nueva estaba supeditado a la compleja y hasta incierta evolución de la política interna. Ante el paulatino desmantelamiento del andamiaje institucional del franquismo - la ley para la Reforma Política de diciembre de 1976 se llegó a conocer como el "harakiri de las Cortes franquistas"-, no fue casual que el embajador mexicano Gómez Gordoa hiciera referencia a la permanente acechanza de golpe de Estado a aquella transición a la democracia que, entre otros menesteres, obligaba a asegurar, en aras de su credibilidad, la participación en el juego político de partidos como el comunista de Santiago Carrillo.

De hecho, México también contribuyó al éxito de aquella transición democrática, asegurando la normalización de sus relaciones con España, por medio de una estrategia de doble cara: primera, cancelando sus relaciones con el gobierno de la Repúbli-

67 En este sentido, resulta muy interesante la valoración que en su día nos avanzó Carlos Seco Serrano al señalar que los reyes de España -Juan Carlos y Sofía- habían sido los primeros monarcas en visitar los países que en otro tiempo fueron las Españas de Ultramar. Así, "no se ha tratado de un redescubrimiento de aquel continente, sino más bien de un redescubrimiento de España, gracias a la Corona, hecho por los pueblos de América". Seco, 2002: 68 .

68 Informe de la Secretaría de Relaciones Exteriores de México remitido al presidente López-Portillo. Ciudad de México, X-1977. AHGE, Expediente III-4986-1 (segunda parte). 
ca Española en el Exilio y, segunda, estableciendo diez días después sus relaciones con la España juancarlista. Por consiguiente, México acabó respaldando el modelo de Estado español puesto en funcionamiento a la muerte del dictador, por más de que éste estuviera vinculado con el testamento franquista y propusiera la implantación de una democracia y un Estado de Derecho por medio de la vía monárquica. En tan sólo unos días, el México de López-Portillo dejaba de ser pro republicano español (del exilio) para convertirse en el aval de aquella transición democrática, monárquica y juancarlista. Por eso, aquel 28 de marzo de 1977, y en París, México y España no sólo lograron establecer sus relaciones diplomáticas en un franco clima de entendimiento recíproco, sino que ambos países daban carpetazo al lacerante episodio de la Guerra Civil española (exilio republicano español, incluido). El pragmatismo de los actores políticos -el presidente López-Portillo, el rey Juan Carlos y el presidente Suárez- les llevó a hacer tabla rasa del pasado, despejar cuantos obstáculos se antepusieran para asegurar el porvenir de unas relaciones bilaterales que, desde el primer momento, tuvieron un marcado sesgo económico y comercial.

Bien a través de la embajada de México en Madrid, bien desde las dependencias de la cancillería mexicana, sita en Tlatelolco, se hizo un puntual seguimiento de la vida política española en sus múltiples facetas. Como se ha presentado más arriba, el embajador Gómez Gordoa tuvo un especial contacto personal con los principales líderes políticos de aquella transición democrática. Con ellos, sondeó la marcha de aquella transición hacia la democracia. Sus fuentes de información eran de primera mano. De ahí que hiciera referencia a temas de tanta importancia como el liderazgo político del rey Juan Carlos, del presidente Suárez o de los principales dirigentes políticos como el socialista Felipe González o el comunista Santiago Carrillo. También de las posibilidades abiertas de una alternancia en el poder ante la progresiva descomposición de Unión de Centro Democrático, de la profunda crisis socio-económica abierta y de la búsqueda de soluciones pactadas y materializadas en los llamados Pactos de la Moncloa, de los debates parlamentarios en torno al diseño, discusión y aprobación de una nueva Constitución -la del 6 de diciembre de 1978- o de las presiones que España empezaba a sentir por parte de países como los Estados Unidos para que formase parte de la Alianza Atlántica.

México conoció de cerca y al detalle los pormenores de aquella transición democrática, así como los matices que iba adquiriendo la nueva política exterior de la era juancarlista que, sobre el papel, estaba obligaba a tomar distancias de aquellas directrices que durante 40 años de dictadura habían caracterizado la forma en que España se había relacionado con la comunidad internacional, especialmente, con aquellos países del mosaico "hispanoamericano". Una vez recuperado el pulso diplomático, y más allá de aquel estado de buena esperanza, la Secretaría de Relaciones Exteriores de México advirtió al presidente López-Portillo acerca de la necesidad perentoria de despejar toda sombra de duda en cuanto a una posible recuperación de los viejos patrones paternalistas y colonialistas del franquismo por parte de los arquitectos de la nueva España del rey Juan Carlos.

Por consiguiente, México echó mano del corpus doctrinario de su tradicional nacionalismo revolucionario, sustentado en principios claros desde la Doctrina Carranza de 1918 en torno a la defensa de la soberanía nacional, la no intervención, la libre autodeterminación de los pueblos o el diálogo conciliatorio para la resolución pacífica de los diferendos entre países. Dicho de otro modo, el discurso diplomático mexicano se vertebraría sobre la necesidad de impulsar unas relaciones poliédricas 
siempre con la hermana España, pero nunca con el viejo anacronismo de la Madre Patria.

Para la ocasión, los diferentes líderes se sintieron cómodos echando mano del recurso metafórico del "puente" sobre el Atlántico. Si la propia relación bilateral representaba en sí misma canal de flujo entre ambos países, España se presentó para México como un puente comercial para penetrar en Europa y en el Mediterráneo; por su parte, y secundando este mensaje recíproco, México debía ser para España el puente natural de penetración no sólo en América Latina, sino también en el poderoso vecino del norte: los Estados Unidos. Al socaire del entendimiento y la cooperación, los dos países se disponían a colaborar en beneficio de las partes y, de manera muy especial, de América Latina. No fue casual que ambos fueran los promotores de las cumbres iberoamericanas y ambos los anfitriones de sus dos primeras ediciones.

\section{Referencias bibliográficas}

Areilza, José María. A lo largo del siglo. Barcelona: Planeta, 1992.

Basurto, Luis G. "Magnífico embajador". Excélsior, 8-VIII-1977.

Caciagli, Mario. Elecciones y partidos en la transición española. Madrid: Centro de Investigaciones Sociológicas, 1986.

Colomer, Josep M. La transición a la democracia: el modelo español. Barcelona: Anagrama, 1998.

Cordero Olivero, Inmaculada. El espejo desenterrado: España en México, 1975-1982. Sevilla: Fundación El Monte, 2005.

Del Águila, Rafael - Montoro, Ricardo. El discurso politico de la transición española. Madrid: Centro de Investigaciones Sociológicas, 1984.

Del Arenal, Celestino. "La posición exterior de España”. En Transición política y consolidación democrática. España (1975-1986), compilado por Cotarelo, Ramón. Madrid: Centro de Investigaciones Sociológicas, 1992, 389-430.

- Política exterior de España hacia Iberoamérica. Madrid: Editorial Complutense, 1994.

- Política exterior de España y relaciones con América. Iberoamericanidad, europeización y atlantismo en la política exterior española. Madrid: Siglo XXI de España Editores, 2011.

Delgado Gómez-Escalonilla, Lorenzo. Diplomacia franquista y política cultural hacia Iberoamérica, 1939-1953. Madrid: Consejo Superior de Investigaciones CientíficasCentro de Estudios Históricos, 1988.

- El imperio de papel. Acción cultural y política exterior durante el primer franquismo. Madrid: Consejo Superior de Investigaciones Científicas, 1992.

Fuentes Quintana, Enrique. "De los Pactos de la Moncloa a la Constitución (julio 1977diciembre 1978)". En Economía española de la transición y la democracia, coordinado por García Delgado, José Luis. Madrid: Centro de Investigaciones Sociológicas, 1990, 23-34.

Galvani, Victoria. El Rey y la Comunidad Iberoamericana. Madrid: Fundación CIPIE, 1987.

Gómez Villanueva, Augusto. Nacionalismo revolucionario. Orígenes de la doctrina internacional de la Revolución Mexicana. México: Miguel Ángel Porrúa, 2010.

Jorge, David. Inseguridad colectiva. La Sociedad de Naciones, la guerra de España y el fin de la paz mundial. Valencia. Tirant humanidades, 2016. 
López Nieto, Lourdes. “Las elecciones de la transición”. En Transición politica y consolidación democrática. España (1975-1986), compilado por Cotarelo, Ramón. Madrid: Centro de Investigaciones Sociológicas, 1992, 77-104.

López-Portillo, José. Mis tiempos: biografía y testimonio político (I). México: Fernández editores, 1988.

Maeztu, Ramiro de. "La Hispanidad”. Acción Española, tomo I, n 1, 15 de diciembre (1931), 8-16.

- Defensa de la Hispanidad. Madrid: s. p. i., 1934.

Matesanz, José Antonio. "De Cárdenas a López Portillo: México ante la República Española, 1936-1977”. Estudios de Historia Moderna y Contemporánea de México, vol. VIII (1980), 179-231.

Mesa, Roberto. Democracia y política exterior en España. Madrid: EUDEMA, 1988.

Morán, Fernando. España en su sitio. Barcelona: Plaza \& Janés, 1990.

Ojeda, Mario. Alcances y límites de la política exterior de México. México: El Colegio de México, 2001.

Oreja, Marcelino. “La política exterior en los primeros años de la transición”. En Veinticinco años de Reinado de S. M. Don Juan Carlos I, editado por Real Academia de la Historia. Madrid: España Fórum, 2002, 173-187.

Pardo Sanz, Rosa. Con Franco hacia el Imperio. La política exterior española en América Latina, 1939-1945. Madrid: Universidad Nacional de Educación a Distancia, 1995.

Powell, Charles. España en democracia, 1975-2000. Las claves de la profunda transformación de España. Barcelona: Plaza \& Janés, 2001.

Presidencia de la República. El gobierno mexicano. México: Departamento Editorial de la Presidencia de la República Mexicana, abril, n 5, 1977a.

- El gobierno mexicano. México: Departamento Editorial de la Presidencia de la República Mexicana, octubre, $\mathrm{n}^{\circ} 11,1977 \mathrm{~b}$.

Primo de Rivera, José Antonio. Obras completas. Madrid: Delegación Nacional de Prensa y Propaganda de Falange Española Tradicionalista y de las J.O.N.S., 1941.

Real Academia de la Historia. Veinticinco años de reinado de S. M. Don Juan Carlos I. Madrid: España Fórum, 2002.

Rubio, María Josefa. "Algunos textos significativos de la transición y consolidación de la democracia española”. En Transición política y consolidación democrática. España (1975-1986), compilado por Cotarelo, Ramón. Madrid: Centro de Investigaciones Sociológicas, 1992, 473-487.

Sánchez Andrés, Agustín. "La transición española vista por la revista Siempre”. En Imágenes e imaginarios sobre España en México. Siglos XIX y XX, coordinado por Sánchez Andrés, Agustín - Pérez Vejo, Tomás - Landavazo, Marco. México: Universidad Michoacana de San Nicolás de Hidalgo-Editorial Porrúa, 2007, 635-659.

Sánchez Andrés, Agustín - Herrera, Fabián. Contra todo y contra todos. La diplomacia mexicana y la cuestión española en la Sociedad de Naciones, 1936-1939. Santa Cruz de Tenerife. Ediciones Idea, 2011.

Sánchez Andrés, Agustín - Pérez Herrero, Pedro. Historia de las relaciones entre España y México, 1821-2014. Madrid: Marcial Pons, 2015.

Sánchez Biosca, Vicente. "PCE, Santiago Carrillo: enero de 1977 o el giro sacrificial de la Transición”. Estudios sobre el Mensaje Periodístico, vol. 22, n 1 (2016), 49-76.

Seco Serrano, Carlos. "La monarquía en la transición política y en la España democrática". En Veinticinco años de Reinado de S. M. Don Juan Carlos I, editado por Real Academia de la Historia. Madrid: España Fórum, 2002, 54-68. 
Serra, Mary Carmen - Mejía, José Francisco - Sola Ayape, Carlos (coords.). 1945, entre la euforia y la esperanza: el México posrevolucionario y exilio republicano español. México: Fondo de Cultura Económica-UNAM, 2014.

Sola Ayape, Carlos. Entre fascistas y cuervos rojos: España y México (1934-1975). México: Editorial Porrúa-Tecnológico de Monterrey, 2008.

- El reencuentro de las águilas: España y México (1975-1978). México: Editorial Porrúa, 2009.

- "El presidente José López-Portillo y la reanudación de las relaciones hispano-mexicanas (marzo de 1977)". Historia del Presente, $\mathrm{n}^{\circ} 16$ (2010a), 113-126.

- "Europa y América, al alcance: el concepto puente en la retórica diplomática hispanomexicana". En México y la Unión Europea: un puente de ida y vuelta, coordinado por Sola Ayape, Carlos. México: Editorial Porrúa-Tecnológico de Monterrey, 2010b, 1-27.

- "Sobre fórmulas y puntos de ruptura: la problemática política y diplomática en el proceso de normalización de las relaciones entre México y España”. Foro Internacional, n² 2, vol. 51 (2011), 271-303.

- "El significado de los Pactos de la Moncloa en el ideario político de la transición democrática mexicana". Foro Internacional, n 193, vol. 48-3 (2014), 631-659.

- El tlatoani de Caparroso: José López-Portillo, México y España. México: Editorial Fontamara, 2015a.

- "La transición democrática española vista desde el México de José López-Portillo". Legajos. Boletín del Archivo General de la Nación, $\mathrm{n}^{\circ}$ 7, julio-septiembre (2015b), 61-85.

- (coord.). Los diplomáticos mexicanos y la Segunda República Española (1931-1975). Madrid: Fondo de Cultura Económica, 2016a.

- "De Cárdenas a Echeverría: los 12 puntos de la política exterior de México hacia la España de Franco (1936-1975)". Foro Internacional, n 224, vol. 56-2 (2016b), 321-377.

- La diplomacia real. Los viajes a México de Juan Carlos I, rey de España (1978-2002). Madrid: Marcial Pons, 2018.

Suárez, Adolfo. "La transición en sus planteamientos y en sus resultados". En Veinticinco años de Reinado de S. M. Don Juan Carlos I, editado por Real Academia de la Historia. Madrid: España Fórum, 2002, 105-122. 